\title{
Determinants of None-adherence to antiretroviral therapy among HIV-infected adults in Arba Minch General Hospital, Gamo Gofa Zone, Southern Ethiopia: A case control study
}

\author{
Belay Dagnaw Bitew ${ }^{1}$, Yemane Berehane ${ }^{2}$, Eskezyiaw Agedew Getahun ${ }^{1}$, Direslgne Misker Abyu ${ }^{1}$ \\ ${ }^{1}$ Arba Minch University, Department of Public Health, Arba Minch Ethiopia \\ ${ }^{2}$ Addis Continental Institute of Public Health, Addis Ababa, Ethiopia
}

Email address:

abelay60@gmail.com (B. D. Bitew), yemaneberhane@gmail.com (Y. Berhane), esk1agid@gmail.com (E. A. Getahun), diresmisker@gmail.com (D. M. Abyu)

\section{To cite this article:}

Belay Dagnaw Bitew, Professor Yemane Berehane, Eskezyiaw Agedew Getahun, Direslgne Misker Abyu. Determinants of NoneAdherence to Antiretroviral Therapy among HIV-Infected Adults in Arba Minch General Hospital, Gamo Gofa Zone, Southern Ethiopia: A Case Control Study. American Journal of Health Research. Vol. 2, No. 5, 2014, pp. 234-240. doi: 10.11648/j.ajhr.20140205.13

\begin{abstract}
Background: Non-adherence to antiretroviral therapy is a major challenge to Acquired Immunodeficiency Syndrome (AIDS) care. For Antiretroviral Therapy (ART) to be effective, high level of adherence is required. In spite of this, there is no information on determinant none-adherence to antiretroviral therapy in the study area; therefore this study was conducted to identify predictors of none-adherence to antiretroviral therapy among People Living with HIV/AIDS (PLWHA) in Arba Minch General Hospital. Methods: Unmatched case-control study design was employed on 115 case and 347 controls. Non-adherence to ART is considered as case and adherence to ART is taken as control. Data was collected by using a structured pre-tested questionnaire and by using data abstraction format from ART registration chart. Binary logistic regression analysis was calculated to assess the presence and degree of association between dependent and independent variables; finally multivariate analysis was conducted to identify independent factors for none adherence. Result: From interviewed respondent majority of respondent 304(65.8\%) were females and the rest 158(34.2\%) were males. From all respondent 209(45\%) were in age group 30-39 years. Factors like rural residence 6.30(3.01-13.15), PLWHA who has no family and community support 1.92(1.05-3.51), mobile phone adjusted odds ratio (AOR) 1.20(1.15-3.44)), alcohol drinker 5.88(2.86-12.09), malnutrition 2.83(1.18-6.77) and who consume low dietary diversity 7.18(3.43-15.04) and CD4 Count $<250$ cells $/ \mathrm{mm}^{3} 2.18(1.05-4.50)$ are the major identified significant factors for none adherence to ART treatment in the study area. Conclusion and recommendation: PLWHA, who has no family and community support, rural residence, not utilized mobile phone, alcohol drinker, under nutrition, who consume low dietary diversity and those with low CD4 count are major significant determinant factors for non-adherence to ART treatment. Therefore, the capacity to effectively manage the above critical factor is crucial in the success of antiretroviral therapy.
\end{abstract}

Keywords: Non-Adherence, Antiretroviral Therapy, Case Control, Southern Ethiopia

\section{Background}

Non-adherence to antiretroviral treatment is the condition of missing doses completely, not following information given by physician, as well as taking drugs inappropriately whereas adherence to antiretroviral treatment is taking $95 \%$ or more of the prescribed doses on time and in the correct way, either with or without food [1, 2]. Significant proportions of HIV-infected patients do not reach high levels of adherence and this can lead to devastating public health problems. Non-adherence to HIV medication is a major reason for treatment failure [3, 4]. It range from $30 \%$ to $40 \%$ in the United States of America, Latin America, and Europe and in China; in Botswana 46\% of patients were none adherent by self-report doses. The level of none adherence reported in Addis Ababa 18.8\% based self-report missing dose. Based on the combined indicator of the dose, time and food adherence 
measurement was $27.6 \%$ in Jimma Referral Hospital and 25.8\% in Yirgalem Hospital, South Ethiopia [5-7]. There are many identified factors for none adherence among the most commonly identified are socio-economic factors and social support, drug abuse and alcohol consumption, ART medication side effect and clinical condition of patient (CD4 count, WHO staging ,opportunistic infection), nutritional related factors under nutrition, dietary diversity and feeding frequency [1, 8]. As a report of Arab Minch Hospital data base shows, there is $10 \%$ average nonadherence flow in monthly follow up. As explained above determinant factors are not explored in the study area. Therefore this study aimed to identify factors affecting adherence ART treatment in Arba Minch General Hospital.

\section{Methods and Materials}

\subsection{Study Area, Period and Design}

The study was conducted in Arba Minch General Hospital. It is public Hospital located in Gamo Gofa Zone; Southern part of Ethiopia $505 \mathrm{Km}$ away from Addis Ababa and $275 \mathrm{Km}$ away from Hawassa. It provides general Health care service and higher levels of clinical care for catchment area populations. It has been providing highly active antiretroviral therapy (HAART) for PLWHA Starting from 1996 for retroviral infected adults and pediatric Patients. The study employed unmatched case control study design on adults' clients under ART clinics from December $5 / 2013$ up to February 10/2014.

\subsection{Source and Study Population}

The study participants were HIV/AIDS positive subjects greater than 18 years who were on ART follow up in Arab Minch General Hospital during data collection period. Pregnant mothers, patient who enrolled on ART less than 3 months , missing clinical record, incomplete data and those less than 18 years were exclude from the study.

\subsection{Sample Size Determination}

The sample size was computed by Epi-info version 7 by considering the following assumption a ratio of nonadherent cases to adherent controls of $1: 3$, power $80,95 \%$ confidence interval $(\mathrm{CI})$, and odd ratio $=2$. By considering factors that have association with none adherence from recent study conducted in North Ethiopia and Southern Ethiopia in Yiregalem Hospital [1, 9].

$$
\begin{gathered}
n_{1}=\frac{\left[\frac{Z a}{2} \sqrt{\left(1+\frac{1}{r}\right) P(1-P)}+Z_{\beta} \sqrt{P_{1}\left(1-F_{1}\right)+\frac{P_{2}\left(1-P_{2}\right)}{r}}\right]^{2}}{\left(P_{1}-P_{2}\right)^{2}} \\
r=\frac{n_{2}}{n_{1}} \quad P=\frac{P_{1} \| r P_{2}}{1+r}
\end{gathered}
$$

$\mathrm{n} 1=$ number of cases $=117, \mathrm{n} 2=$ number of controls $=350$ $\mathrm{r}=$ the ratio of cases to controls $=1: 3$ ( 1 None adherence with 3 Adherence).

$\mathrm{P} 1=$ proportion of controls among exposed, $\mathrm{P} 2=$ proportion of cases with exposure

\subsection{Sampling Procedure}

Study participant was selected based on daily follow up of patient in ART clinic. First non-adherence case was identified from ART by reviewing patient registration follow up charts. Patients were selected; who were nonadherent (poor adherence) at least once in the last three visits follow up appointment. In addition to PLWHA who came for ART follow up by missing monthly follow up screening for non-adherence based on self-report missing prescribed dose less than $95 \%$ of the total numbers of the prescribed antiretroviral medication for the last one month were considered as "cases".

\subsection{Data Collection Procedure and Tools}

Interview administered Amharic version questionnaires was used to collect data on socio demographic and others factors related to none adherence; the questionnaire was adapted and modified in to our context from previous literatures [1, 5-8]. Moreover, Human immunodeficiency virus infection (HIV) related clinical information was extracted from ART registration follow up charts by using data abstraction format. Data on dietary diversity and meal frequency was collected by allowing participant freely to recall the number of meal frequency and food Varity consumed within 24 hours with the help of 12 item questions developed for household and individuals dietary diversity scale prepared by FAO and FANTA. Weight of participants was measured by using standard beam balance and the scale was checked at zero before and after each measurement. Participants' weight was measured after removing heavy clothes and was recorded to the nearest $0.1 \mathrm{~kg}$. Height of participant was measured by using the standard measuring scale to the nearest $0.01 \mathrm{~cm}$. Four unemployed female diploma nurses recruited as data collectors, and two BSc nurse supervised the data collection. Training was given for data collectors and supervisors.

\subsection{Data Quality Control}

Pre testing of the questionnaire was conducted on 20 clients in Arba Minch town Health Center a week prior to the actual study; and necessary modification is done according to the gap identified. Interview of participants was carried out in private room. Data collection process was strictly followed day to day by the supervisor and principal investigators and the collected data was checked for completeness and consistency every day by supervisors and principal investigators.

\subsection{Data Analysis and Handling}

Data was coded and entered into epinfo version 6.0 exported to SPSS Version 20 for analysis. Univariate 
analysis was conducting to describe the study population in relation to relevant variables. Bivariate analysis undertaken to assess the presence and degree of association between dependent and independent variables; finally factors that shows association in bivariate analysis and which has Pvalue less than 0.2 entered in to multiple logistic regression model for controlling confounding factors and to identify significant factors. At the end AOR with 95\% CI, P-value $<0.05$ was considered as significant.

Assessment of dietary diversity was analyzed by categorizing in to three levels as $<=3$ food items as low , 46 food items as medium and $\geq 6$ food items as higher level and meal frequency was measured as low when the clients eat less than 3 meals and High when they eat $>=3$ meal frequency per 24 Hours. Nutritional statues measured by using WHO BMI classification by taking $<18.5 \mathrm{~kg} / \mathrm{m} 2$ as under-nutrition, $18.5 \mathrm{~kg} / \mathrm{m} 2-24.99 \quad \mathrm{~kg} / \mathrm{m} 2$ taken as normal $>=25 \mathrm{~kg} / \mathrm{m} 2$ as pre obesity.

\subsection{Operational Definition}

Adherence to ART (Control): - is defined as taking one's medicine as prescribed and agreed between the patient and provider which is $95 \%$ or more adherences to ART. Which means taking doses no more than two hours before or two hours after the time of a doctor's advice to take doses (95\% or more adherence $=$ missing $\leq 2$ doses of 30 doses or $\leq 3$ doses of 60 doses) $[1,4]$.

Non-adherence to ART (Case): - is the condition of missing doses completely, not following information given by physician, as well as taking drugs inappropriately. Which means taking doses two or more hours before, and/or two or more hours after the time of a Doctor's advice to take doses or missing doses completely (less than $95 \%$ adherence $=$ missing $>2$ doses of 30 doses or $>3$ doses of 60 doses $[1,4]$.

'Meal frequency - is the number of reported daily eating occasions by PLWA in a household experienced within a day. This does not include eating occasions experienced outside home. It classified as good when it is 3 and above with additional snack and poor when it is below 3 meals per day based on HIV/AIDS guide line recommendation.

Dietary diversity - is the number of reported different foods and food groups consumed in a household over a 24hour period. This does not include food group consumed outside home. It is classified as low $<3$ food items, medium $4-6$ food items and $\geq 6$ food items as higher based on FAO recommendation [6].

\subsection{Ethical Consideration}

Ethical clearance was obtained from Addis Continental Institute of Public Health. Permission letter was obtained from Arab Minch University post graduate public Health coordinating office and Arba Minch General Hospital. Verbal consent was taken from each participant after clearly explaining the purpose of the study. They were informed to withdraw from study at any time and/or to refrain from responding to questions if they were not interest to participate by any reason. Confidentiality of the data file obtained from respondents was kept in secure place by using codes instead of any personal identifiers.

\section{Results}

From interviewed participated in the present study $347(75.1 \%)$ from adherent group and $115(24.9 \%)$ were from non-adherent group with response rate of $98.93 \%$. Majority of respondent $304(65.8 \%)$ were females and the rest $158(34.2 \%)$ were males. From all respondent 209(45\%) were in age group 30-39 years. Among the study participants $375(81.17 \%$ ) were urban and the rest live in rural .Almost half of study participant were daily workers in there occupational statues and 179(38.7) were educated up to primary school and one third of them were not read and write (table 1).

Table 1. Socio-demographic characteristics of the study participants in Southern Region, Gamo Gofa Zone in Arba Minch General Hospital, 2014

\begin{tabular}{|c|c|c|c|}
\hline Variable & None adherence & Adherence & Total Frequency \% \\
\hline \multicolumn{4}{|l|}{ Sex } \\
\hline Male & $52(45.22)$ & $106(30.55)$ & $158(34.2)$ \\
\hline Female & $63(57.78)$ & $241(69.45)$ & $304(65.8)$ \\
\hline \multicolumn{4}{|l|}{ Age } \\
\hline $18-29$ years & $37(32.2)$ & $80(23.00)$ & $117(25.33)$ \\
\hline $30-39$ years & $52(45.22)$ & $157(45.25)$ & $209(45.24)$ \\
\hline 40 - 49 years & $17(14.78)$ & $64(18.44)$ & $81(17.32)$ \\
\hline$>50$ years & $9(7.80)$ & $46(13.12)$ & $55(11.90)$ \\
\hline \multicolumn{4}{|l|}{ Residence } \\
\hline Rural & $40(34.78)$ & $47(13.55)$ & $87(18.83)$ \\
\hline Urban & $75(65.22)$ & $300(86.45)$ & $375(81.17)$ \\
\hline \multicolumn{4}{|l|}{ Religion } \\
\hline Protestant & $23(2.00)$ & $92(26.51)$ & $116(24.10)$ \\
\hline Orthodox & $86(74.78)$ & $246(70.89)$ & $332(71.9)$ \\
\hline Muslim & $5(23.22)$ & $9(2.60)$ & $14(3.00)$ \\
\hline Education & & & \\
\hline
\end{tabular}




\begin{tabular}{llll}
\hline Variable & None adherence & Adherence & Total Frequency \% \\
\hline Not read and write & $51(44.35)$ & $90(25.94$ & $141(30.50)$ \\
Read and write & $4(3.48)$ & $17(4.90)$ & $21(4.50)$ \\
Primary school & $39(31.30)$ & $140(40.35)$ & $179(38.70)$ \\
Secondary and above & $21(18.26)$ & $100(28.80)$ & $121(26.20)$ \\
Occupation & & & \\
Daily laborer & $73(63.48)$ & $146(40.08)$ & $219(47.40)$ \\
Self employed/business & $24(20.87)$ & $100(28.82)$ & $124(26.84)$ \\
Government employed & $18(15.65)$ & $101(31.10)$ & $119(25.76)$ \\
\hline
\end{tabular}

The major reasons raised by respondent for missing of prescribed pills are forget the time, away from home and busy with other work are major reasons raised by respondent (fig 1).

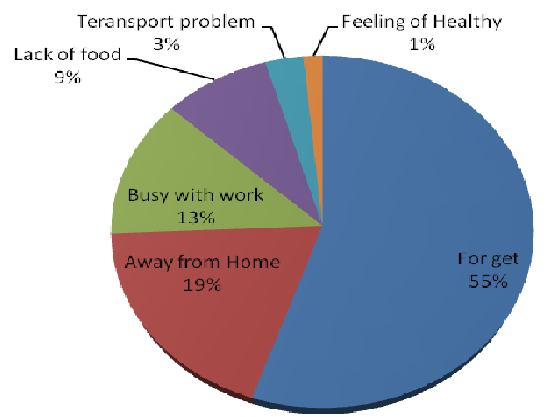

Fig 1. Justification given by respondents for missing prescribed pills In Arba Minch General Hospital, 2014.

\subsection{Factors Affecting Non-Adherent to ART Treatment}

After applying bivariate and multiple logistic regressions; factors like rural residence 6.30(3.01-13.15), PLWHA who has no family and community support 1.92(1.05-3.51), those who has no mobile phone AOR 1.20(1.15-3.44)), alcohol drinker 5.88(2.86-12.09), malnutrition 2.83(1.186.77)and who consume low dietary diversity 7.18(3.4315.04) and CD4 count $<250$ cells $/ \mathrm{mm} 32.18(1.05-4.50)$ are the major identified significant factors for non-adherence to ART treatment in the study area (table 2).

Table 2. Bivariate and multivariate analysis between explanatory variables and none adherence to ART among study participants in Arba Minch General Hospital, 2014

\begin{tabular}{|c|c|c|c|c|c|}
\hline \multirow{3}{*}{$\begin{array}{l}\text { Explanatory Variable } \\
\text { Variables }\end{array}$} & \multicolumn{2}{|c|}{ Adherence statues } & \multirow{3}{*}{ Crude OR (95\% CI) } & \multirow{3}{*}{ Adjusted OR (95\% CI) } & \multirow{3}{*}{$\begin{array}{l}\text { AOR } \\
\text { P-value }\end{array}$} \\
\hline & Non adherent & Adherence & & & \\
\hline & (1) & (0) & & & \\
\hline \multicolumn{6}{|l|}{ Sex } \\
\hline Male & $52(45.2)$ & $106(30.5)$ & $1.88(1.23-2.89)$ & $1.35(0.69-2.63)$ & \multirow{2}{*}{0.39} \\
\hline Female & $63(54.8)$ & $241(69.5)$ & 1 & 1 & \\
\hline \multicolumn{6}{|l|}{ Residence } \\
\hline Rural & $40(34.8)$ & $47(13.5)$ & $3.40(2.08-5.56)$ & $* * 6.30(3.01-13.15)$ & \multirow{2}{*}{0.001} \\
\hline Urban & $75(62.2)$ & $300(86.5)$ & 1 & 1 & \\
\hline \multicolumn{6}{|l|}{ Education level } \\
\hline Not read and write & $51(44.3)$ & $90(25.9)$ & $2.69(1.50-4.83)$ & $1.14(0.46-2.86$ & \multirow{4}{*}{$\begin{array}{l}0.77 \\
0.64 \\
0.34\end{array}$} \\
\hline Read and write & $4(3.5)$ & $17(4.9)$ & $1.12(0.34-3.67)$ & $0.69(0.15-3.18)$ & \\
\hline Primary school & $39(33.9)$ & $140(40.3)$ & $1.32(0.74-2.39)$ & $1.47(0.66-3.25)$ & \\
\hline Secondary and above & $21(18.3)$ & $100(28.9)$ & 1 & 1 & \\
\hline \multicolumn{6}{|l|}{ Occupational statues } \\
\hline Daily laborer & $73(33.9)$ & $146(42)$ & $2.80(1.58-4.98)$ & $1.73(0.84-3.57)$ & \multirow{3}{*}{0.14} \\
\hline Self employed/business & $24(20.9)$ & $100(28.8)$ & $1.34(0.68-2.63)$ & $0.751(0.33-1.70)$ & \\
\hline Government employed & $18(45.2)$ & $101(28.2)$ & 1 & 1 & \\
\hline \multicolumn{6}{|l|}{ Media exposure } \\
\hline Yes & $39(33.9)$ & $186(53.6)$ & 1 & 1 & \\
\hline No & $76(66.1)$ & $161(40.4)$ & $2.25(1.45-3.49)$ & $0.69(0.34-1.42)$ & 0.31 \\
\hline \multicolumn{6}{|l|}{ Working Hours } \\
\hline$\leq 8$ Hours & $74(63.3)$ & $153(44.0)$ & 1 & 1 & \\
\hline$>8$ Hours & $41(36.7)$ & $194(56.0)$ & $2.30(1.47-3.54)$ & $1.12(0.96-2.78)$ & 0.68 \\
\hline \multicolumn{4}{|l|}{ Mobile phone } & \multirow{3}{*}{$\begin{array}{l}1 \\
* * 1.20(1.15-3.44)\end{array}$} & \multirow{3}{*}{0.014} \\
\hline Yes & $41(35.6)$ & $213(61.4)$ & 1 & & \\
\hline No & $74(64.4)$ & $134(38.6)$ & $2.85(1.85-4.44)$ & & \\
\hline \multicolumn{6}{|c|}{ Getting community /Family support } \\
\hline Yes & $77(66.9)$ & $292(84.2)$ & 1 & 1 & \\
\hline No & $38(33.1)$ & $55(15.8)$ & $2.62(1.61-4.25)$ & $* * 1.92(1.05-3.51)$ & 0.035 \\
\hline
\end{tabular}

\footnotetext{
${ }^{* *}$ Significant factors in multiple logistic regressions
} 
Table 2. Continued ...

\begin{tabular}{|c|c|c|c|c|c|}
\hline \multirow{3}{*}{ Explanatory Variable } & \multicolumn{2}{|c|}{ Adherence statues } & \multirow{3}{*}{$\begin{array}{l}\text { Crude OR } \\
\text { COR(95\% CI) }\end{array}$} & \multirow{3}{*}{$\begin{array}{l}\text { Adjusted OR } \\
\text { AOR (95\% CI) }\end{array}$} & \multirow{3}{*}{ P-value } \\
\hline & Non-adherent & Adherent & & & \\
\hline & (1) & (0) & & & \\
\hline \multicolumn{6}{|l|}{ Side effect of drugs } \\
\hline Yes & $53(46)$ & $100(28.8)$ & $2.11(1.37-3.26)$ & \multirow{2}{*}{$1.19(0.64-2.26)$} & \multirow{2}{*}{0.58} \\
\hline No & $62(54)$ & $247(71.2)$ & 1 & & \\
\hline \multicolumn{6}{|l|}{ Alcohol drinking } \\
\hline Yes & $28(24.3)$ & $27(7.8)$ & $3.81(2.14-6.80)$ & $* * 5.88(2.86-12.09)$ & \multirow{2}{*}{0.001} \\
\hline No & $87(75.7)$ & $320(92.2)$ & 1 & 1 & \\
\hline \multicolumn{6}{|l|}{ Meal frequency } \\
\hline$\leq 2$ meals & $23(20)$ & $45(12.9)$ & $2.19(1.18-4.03)$ & $0.94(0.49-1.79)$ & \\
\hline 3 Meals & $53(46)$ & $135(38.9)$ & $1.68(1.05-2.69)$ & $0.38(0.18-0.92)$ & 0.032 \\
\hline 3 Meals with sank & $39(24)$ & $167(48.2)$ & 1 & & \\
\hline \multicolumn{6}{|c|}{ Nutritional statues(BMI) } \\
\hline$\leq 18.5$ & $27(14.8)$ & $53(15.3)$ & $2.29(1.12-4.680$ & $* * 2.83(1.18-6.77)$ & 0.01 \\
\hline $18.6-24.99$ & $72(62.6)$ & $222(63.9)$ & $1.46(0.79-2.66)$ & $1.34(0.64-2.82)$ & 0.40 \\
\hline$\geq 25$ & $16(22.6)$ & $72(20.8)$ & 1 & 1 & \\
\hline \multicolumn{6}{|l|}{ Dietary diversity } \\
\hline$\leq 3$ food groups & $38(33)$ & $34(9.8)$ & $8.85(4.75-16.49)$ & $* * 7.18(3.43-15.04)$ & 0.001 \\
\hline 4-5 food groups & $52(45.2)$ & $115(33.1)$ & $3.58(2.10-6.08)$ & $* * 3.50(1.89-6.48)$ & 0.001 \\
\hline$\geq 6$ food groups & $25(21.2)$ & $198(57.1)$ & 1 & 1 & \\
\hline \multicolumn{6}{|l|}{ WHO stage } \\
\hline Stage I & $68(59.1)$ & $271(78)$ & 1 & 1 & 1 \\
\hline Stage II & $29(25.2)$ & $49(14.1)$ & $2.36(1.39-4.01)$ & $0.18(0.02-1.36)$ & 0.09 \\
\hline Stage III & $13(11.3)$ & $25(7.2)$ & $2.07(1.01-4.26)$ & $0.24(0.03-1.90)$ & 0.17 \\
\hline Stage IV & $5(4.4)$ & $2(0.7)$ & $2.35(1.38-4.01)$ & $0.14(0.02-1.27)$ & 0.08 \\
\hline \multicolumn{6}{|c|}{ Recent Opportunistic infection } \\
\hline Yes & $50(43.5)$ & $114(32.9)$ & $1.57(1.02-2.42)$ & $1.00(0.51-1.95)$ & 1.00 \\
\hline No & $65(56.50$ & $233(67.1)$ & 1 & 1 & \\
\hline \multicolumn{6}{|l|}{ Recent CD4 Count } \\
\hline$\leq 250$ & $25(21.7)$ & $42(12.1)$ & $1.17(0.73-1.88)$ & $0.83(0.46-1.49)$ & 0.04 \\
\hline $251-500$ & $49(42.6)$ & $154(44.4)$ & & $0.03(0.40-1.49)$ & 0.85 \\
\hline$\geq 501$ & $41(35.7)$ & $151(43.5)$ & $\begin{array}{l}1 \\
1\end{array}$ & 1 & \\
\hline
\end{tabular}

${ }^{\text {** }}$ Significant factors in multiple logistic regressions

\section{Discussion}

This study focused on determinant factors affecting none adherence to ART among adult people living with HIV who take antiretroviral therapy. From socio demography factors those who are rural are more likely none adhere than their counter part, these finding is supported by other similar studies $[8,9]$. But from occupational status, those daily workers do not show significant association; this finding is consistent with study conducted in Eastern Tanzania and North Ethiopia [1, 2].

Patients who had no family and social support were 1.92(1.05-3.51) times more likely to be none adhere to ART as compared to those who get materials, financial and advice from their family, religious and social organization; this finding is similar and consistent with other findings [10-12].Social support enhance adherence through encouragement, reassurance, reinforcement, and motivation of to take their drugs properly and regularly by masking the effect of stigma, stress, anxiety and depression [2].

Participant who has no mobile phone 1.20(1.15-3.44)) times more likely to be none adhere to ART as compared to their counterpart. This finding is consistent with other studies [7, 12, 13]. Mobile phone alarms serve as reminders for the patient helps to remember medication time easily
[13, 14]; in addition mobile phone is essential tool for adherence supporters to call patients when they miss their monthly appointment.

Alcohol consumers are 5.88(2.86-12.09) times more likely none adhere to ART as compared to none drinker. These finding is consistent with study done in Eastern Tanzania, Botswana, Cameroon, Northern Ethiopia [1, 2, 4, 15]. Drug abuse and alcohol consumption further threaten proper adherence; active alcohol or substance abuse makes it more difficult for patients to adhere to treatment. Alcohol use can result into forgetfulness of the dose timing and dietary instructions that accompany some antiretroviral medications [2]. Excessive alcohol use can cause liver damage, increase liver enzymes which lead to short drug's half-life than expected. Besides, alcohol exacerbates antiretroviral drug side effects.

Among nutritional related factors; malnutrition (which is defined as $\mathrm{BMI}<18.5 \mathrm{Kg} / \mathrm{m}^{2}$ ) was significantly associated with non-adherence to ART. This result is similar and supported by a study conducted in Zambia, Uganda, Northern and Southern Ethiopia [1, 16-18]. Better nutritional status could enhance adherence to ART[1, 19].People living with HIV infection exposed to impaired productivity and declining income these condition enforce them to feed low diet quality and quantity food ;finally 
result malnutrition along with HIV infection [17, 20, 21].

Respondent who feed low dietary diversity of food in the last 24 hours were more likely non-adhere to ART than their counterpart. The result is supported by the study done in Peru, Uganda [21, 22]; respondent who did not afford balanced meals. Feeding diversified food improve quality and nutritional content of foods and furthers enhance nutritional statues of patients result for better adherence to ART $[1,17,19,20]$.

Among Clinical, Medication and drug side effect factors CD4 count less than 250 cells $/ \mathrm{mm}^{3}$ more likely none adhere to ART as compared to their counterpart; the finding is consistent with another study[1]. From all non-adherence cases in the current study $74(64.3 \%)$ of them have CD4 count less than 500 cells $/ \mathrm{mm}^{3}$.

In this study opportunistic infection, WHO stage and drugs side effect did not show significant association to none adherence in multivariate analysis these finding is contradicted with others studies [5, 9, 12, 19, 23-25]. In addition majority of the patient take ART medication for long time; they tolerate and adapted drug side effects along with Health professional advice about the side effect of drugs.

\section{Conclusion}

PLWHA who has no family and community support, who live in rural area, not utilized mobile phone, alcohol drinker, malnourished, who consume low dietary diversity and with low CD4 counts are the major significant factors for None adherence to ART treatment.

\section{Strength and Limitation of the Study}

Has better strength to identify multiple and Varity of factors for none adherence to ART treatment specifically socio demography, Nutritional related factors and HIV clinical factors. In addition the data was collected by using different tools like structured interviewed questioners, by direct measuring the Height and Wight by using standard measuring scale and by using data abstraction format this increase internal validity.

The limitation of this study was; it does not include institutional and Health profession related effect on none adherence. It may be affected in some extent by social desirable and recall bias; even it was minimized by different strategy like interviewing in private rooms, by probing to recall freely the frequency and variety food consumed in 24 hours.

\section{Recommendation}

\section{For Health Professional}

- The adherence supporters should give technical support for PLWHA to take drugs on work place.

- Health professional and Adherence supporters should adjust and give direction; for RVI patient to have cost effective multiple reminder methods.

\section{For Government and NGOS}

- Focus on developing and well integration of alternative income generating activities and social supports to ART programs for PLWHA to improve their nutritional statues and dietary quality based on local context; instead of distributing food supplementation; to improve adherence and to reduce burden of HIV/ADIS on community.

\section{For Researchers}

- $\quad$ Further study should be carried out in longitudinal base by integrating with qualitative study design to understand deeply socio-cultural and behavioral related factors towards None adherence because ART adherence is dynamic and its factors are modifiable from time to time.

\section{Abbreviations}

ART-Anti Retroviral Therapy, ARV-Antiretroviral, HAART-Highly Active Anti Retroviral Therapy, PLWHAPeople living with HIV/AIDS, BMI-Body mass index

\section{Acknowledgements}

We are greatly indebted to thank all respondents for their willingness to participate in the study. Our deepest gratitude goes to our data collectors and Arba Minch Hospital manager.

\section{Competing interest}

The authors declare that they have no competing interest.

\section{Authors' Contributions}

BD: Initiated the research, wrote the research proposal, conducted the research, did data entry and analysis and wrote the manuscript. YB: contributed in the designing of methods and data analysis. EA: contributed in the designing of methods, data analysis and write up of proposal. DM: Involved in designing in Methodology and data analysis.

\section{References}

[1] Berhe, N., D. Tegabu, and M. Alemayehu, Effect of nutritional factors on adherence to antiretroviral therapy among HIV-infected adults: a case control study in Northern Ethiopia. BMC infectious diseases. 13(1): p. 233.

[2] Idindili, B., et al., A case-control study of factors associated with non-adherent to antiretroviral therapy among HIV infected people in Pwani Region, eastern Tanzania. Tanzania Journal of Health Research. 14(3). 
[3] Wakibi, S.N, Z. Nga, and G.G. Mbugua,Factors associated with non-adherence with highly active antiretroviral therapy in Nairobi, Kenya. AIDS Res Ther. 8: p. 43.

[4] Mbuagbaw, L., et al., Trends and determining factors associated with adherence to antiretroviral therapy (ART) in Cameroon: a systematic review and analysis of the CAMPS trial. AIDS Res Ther. 9(1): p. 37.

[5] Tadios, Y. and G. Davey, Antiretroviral treatment adherence and its correlates in Addis Ababa, Ethiopia. Ethiopian medical journal, 2006. 44(3): p. 237-244.

[6] FAO, Baseline Survey Report Protecting and Improving Household Food Security and Nutrition in HIV/AIDS Affected Areas in Manica and Sofala Province, Maputo, Mozambique. 2006.

[7] Tiyou A, et al., Predictors of adherence to antiretroviral therapy among people living with HIV/AIDS in resource limited setting of southwest Ethiopia. . AIDS Research and Therapy 2010. 7(39).

[8] Ayalu A, Reda Biad, and gilign S, Determinants of Adherence to Antiretroviral Therapy among HIV Infected Patients in Africa, AIDS Research and Treatment. 2012.

[9] Markos, E., A. Worku, and G. Davey, Adherence to ART in PLWHA and Yirgalem Hospital, South Ethiopia. Ethiopian Journal of Health Development, 2009. 22(2): p. 174-179.

[10] Teferra, S., et al., Perspectives on reasons for non-adherence to medication in persons with schizophrenia in Ethiopia: a qualitative study of patients, caregivers and health workers. BMC psychiatry. 13(1): p. 168.

[11] Sanjobo, N., J.C. Frich, and A. Fretheim, Barriers and facilitators to patients $\mid$ 'adherence to antiretroviral treatment in Zambia: a qualitative study. SAHARA J (Journal of Social Aspects of HIV/AIDS Research Alliance), 2009. 5(3): p. 136-143.

[12] Mukhtar-Yola, M., et al., Preliminary investigation of adherence to antiretroviral therapy among children in Aminu Kano Teaching Hospital, Nigeria. African Journal of AIDS Research, 2006. 5(2): p. 141-144.

[13] Tran, B.X., et al., Determinants of antiretroviral treatment adherence among HIV/AIDS patients: a multisite study. Glob Health Action. 6(19570): p. 19570.

[14] Huang D, et al., Effects of a Phone Call Intervention to Promote Adherence to Antiretroviral Therapy and Quality of
Life of HIV/AIDS Patients in Baoshan,China: A Randomized Controlled Trial . Hindawi Publishing Corporation AIDS Research and Treatment., 2013.

[15] Ehlers J and D.W. M., Patients adherence to anti-retroviral therapy in Botswana.Journal of Nursing Scholarship., 2009. 41(2): p. 149-157.

[16] Cantrell, R.A., et al., A pilot study of food supplementation to improve adherence to antiretroviral therapy among food insecure adults in Lusaka, Zambia. Journal of acquired immune deficiency syndromes (1999), 2008. 49(2).

[17] Daniel, M., F. Mazengia, and D. Birhanu, Nutritional status and associated factors among adult HIV/AIDS clients in Felege Hiwot Referral Hospital, Bahir Dar, Ethiopia. Science. 1(1): p. 24-31.

[18] Nyanzi-Wakholi, B., et al., The charms and challenges of antiretroviral therapy in Uganda: the DART experience. AIDS care. 24(2): p. 137-142.

[19] Hailemariam, S., G.T. Bune, and H.T. Ayele, Malnutrition: Prevalence and its associated factors in People living with HIV/AIDS, in Dilla University Referral Hospital. Archives of Public Health. 71(1): p. 13.

[20] Ivers, L.C., et al., HIV/AIDS, undernutrition, and food insecurity. Clinical Infectious Diseases, 2009. 49(7): p. 1096-1102.

[21] Molly F, et al., Food Insufficiency is a Risk Factor for Suboptimal Antiretroviral Therapy Adherence among HIVInfected Adults in Urban Peru. AIDS Behav, 2011. 15(7): p. 1483-1489.

[22] Nyanzi-Wakholi B, et al., The charms and challenges of antiretroviral therapy in Uganda: the DART experience. AIDS Care 2012. 24(2): p. 137-142.

[23] Adriana A, Paola TM, and Rita M, Correlates and predictors of adherence to Highly Active Antiretroviral Therapy. JAIDS 2002.

[24] Mangili, A., et al., Nutrition and HIV infection: review of weight loss and wasting in the era of highly active antiretroviral therapy from the nutrition for healthy living cohort. Clinical Infectious Diseases, 2006. 42(6): p. 836-842.

[25] Prosperi, M.C., et al., Predictors of first-line antiretroviral therapy discontinuation due to drug-related adverse events in HIV-infected patients: a retrospective cohort study. BMC infectious diseases. 12(1): p. 296. 